\title{
FULL MOUTH REHABILITATION OF SEVERELY WORN DENTITION WITH LOSS OF VERTICAL DIMENSION- A CASE REPORT
}

\author{
Dr. Rajdeep Tah, Dr. Ahila Singaravel Chidambaranathan, Dr. Muthukumar Balasubramanium \\ Department of Prosthodontics. SRM Dental College, SRM University, Ramapuram, Chennai, India.
}

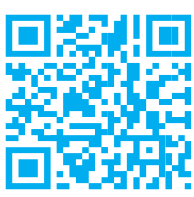

DOI: 10.37841/jidam_2021_V8_I3_07

Address for Correspondence

Dr.S.C.Ahila, MDS.,

Professor, Department of Prosthodontics,

SRM Dental College, Ramapuram, Chennai, India.

Mail id: ahilasc@yahoo.co.in

Received: 12.12.2020

First Published: 30.08.2021

Accepted: 24.08.2021

Published: 27.09.2021

\section{ABSTRACT}

Prosthetic rehabilitation of severely attritted teeth with loss of vertical dimension is a real challenge due to little space available for rehabilitation. A valid treatment modalities is needed to increase the VDO to enable space for the prosthesis to enhance aesthetic, maintain anterior teeth relationships, and minimize the need for invasive procedures and endodontic treatments. Proper diagnosis and treatment sequences necessary to obtain successful results. This clinical report showed the successful management of badly mutilated dentition using conventional method

KEYWORDS: Attrition, Full mouth rehabilitation, Mutilated Dentition, Vertical Dimension at Occlusion 
Rajdeep Tah et al: Full Mouth Rehabilitation Of Severely Worn Dentition With Loss Of Vertical Dimension

\section{INTRODUCTION:}

The wear of occlusal surfaces of teeth is a continuous process throughout the life of a patient. The wear of occlusal surface result in pulpal trauma, occlusal disharmony, impaired function, and esthetic disfigurement. ${ }^{1}$ Tooth wear can be attrition, abrasion, and erosion. Therefore, it is important to identify the factors which contribute to excessive wear and reduce the vertical dimension of occlusion (VDO). ${ }^{2}$

Rehabilitation of mutilated dentition with missing teeth using fixed or removable prostheses has been a challenge to dental practitioners. Fixed prosthesis offers exceptional satisfaction for the patient as well as the dentist which will transform an unhealthy, unaesthetic dentition into a comfortable, capable of function for years and enhancing esthetics. ${ }^{3,4}$

The classification proposed by Turner and Missirlian ${ }^{1}$ Category-1: Excessive wear with loss of vertical dimension of occlusion (VDO), Category-2: Excessive wear without loss of VDO but with space available, Category-3: Excessive wear without loss of VDO but with limited space. This case report describes full-mouth rehabilitation of worn out dentition with loss of vertical dimension using conventional method to produce satisfied aesthetic and function

\section{CASE REPORT}

A 65 years old male patient reported to the Department of Prosthodontics, SRM Dental College, Ramapuram, Chennai, India with the complaints of severely damaged teeth with difficulty in chewing and sensitivity. On clinical examination 12, 24,25,26,27 are missing in maxillary arch, classified as Kennedy's class III partial edentulous space and 44,45,46,47,35,36,37 in Mandible, classified as Kennedy's class I partial edentulous space. The clinical condition is coming under Turner's category No 1: Excessive wear with loss of vertical dimension of occlusion ${ }^{1}[$ Fig.1]. Treatment plan explained to the patient was cost post on 11,21,12 with long span FPD from 16 to 28 and root canal treatment for the mandibular teeth with FPD in relation to 43,42,41 and $31,32,33,34,35$ with removable partial denture for distal extension space. The treatment procedure was started after obtaining informed consent from the patient.



Fig 1: Pre-operative (Intra-oral view)

\section{PROCEDURE:}

Diagnostic impression was made with irreversible hydrocolloid impression material (Zelgan Plus Alginate Impression Material, Dentsply,India) and the casts were poured using Type II gypsum product (Golden Stone, Golden Stone Ramaraju Traders, Chennai) and mounted on a semi-adjustable articulator Hanau spring bow (R035203),USA.A face bow transfer was done to mount the maxillary cast in the semi adjustable articulator. The existing centric bite of the patient was used to mount the mandibular cast. The space analysis was done in the articulated cast.

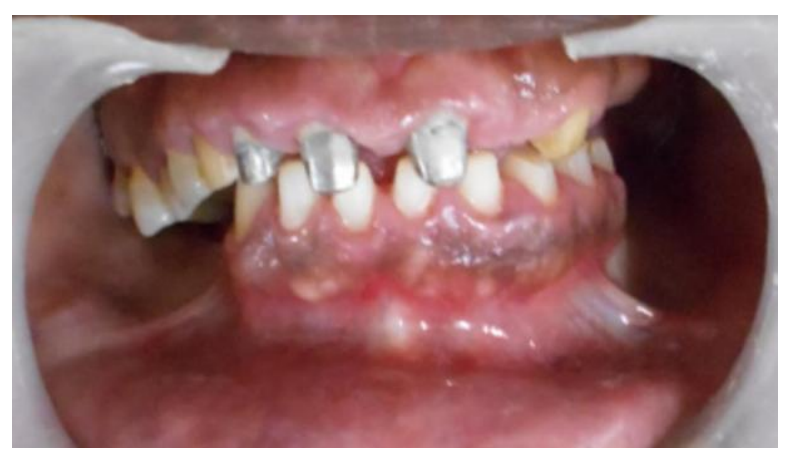

Fig 2: Coping fixed on the abutment teeth 11, 21



Fig 3: Inter-occlusal record with Lucia Jig 
Rajdeep Tah et al: Full Mouth Rehabilitation Of Severely Worn Dentition With Loss Of Vertical Dimension

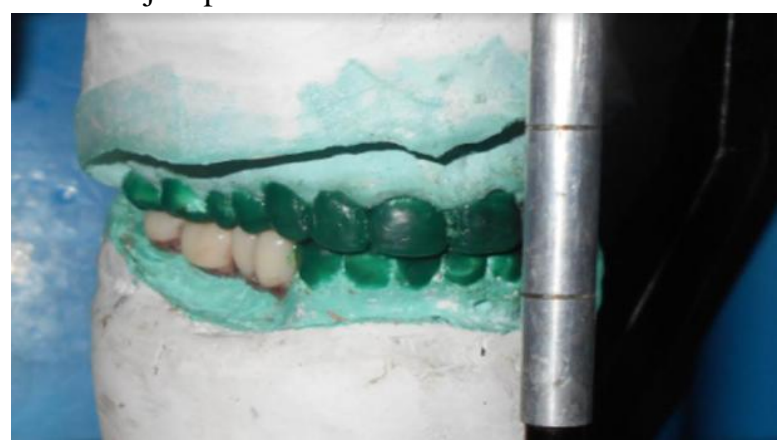

Fig 4: Wax Pattern for provisional restoration

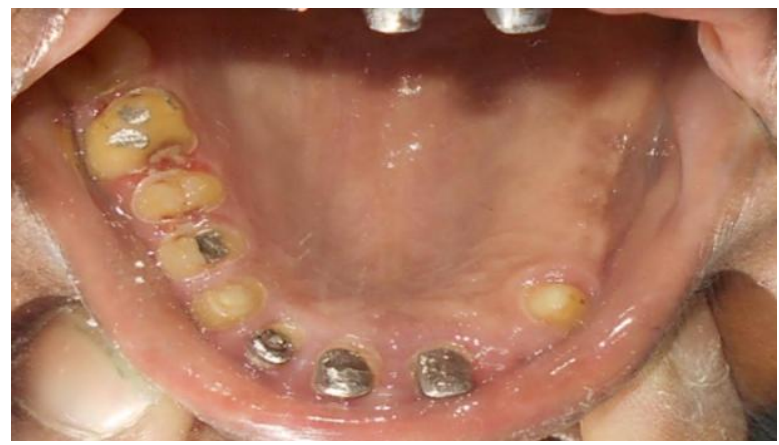

Fig 5: Tooth preparation of maxillary teeth

After root canal treatment of maxillary anterior teeth, cast post was done on 11,21,12 [Fig.2] then temperory crown was fabricated using tooth color acrylic.(Dental products of India).A lucia jig with $2 \mathrm{~mm}$ thickness was fabricated using auto polymerized acrylic resin (DPI, India).Then tooth preparation was done on lower anterior teeth, the bite was registered with Bonabite bite vinyl polysiloxane registration paste (DMP, Europe)[Fig.3] and mounted in a semi-adjustable articulator Hanau spring bow (R-035203).The wax pattern for temporary crown was fabricated [Fig.4] and duplicated with silicone putty material (Aquasil, Dentsply Intl, New York, PA).Tooth preparation for all the remaining teeth had been done [Fig.5] and jaw relation was done with the lucia jig and mounted in semi-adjustable articulator.

In the articulated with an increased OVD, the occlusal plane was established with Broad-rick occlusal plane analyzer. This plane was used as a guide during mock wax-up. The mock wax-up was used for putty index from which the fabrication of temporary restoration was done. Then the provisional restoration was fabricated using tooth color acrylic resin.(Dental products of India) and luted with intermediate restorative material.(IRM, Dentsply, India)[Fig.6].

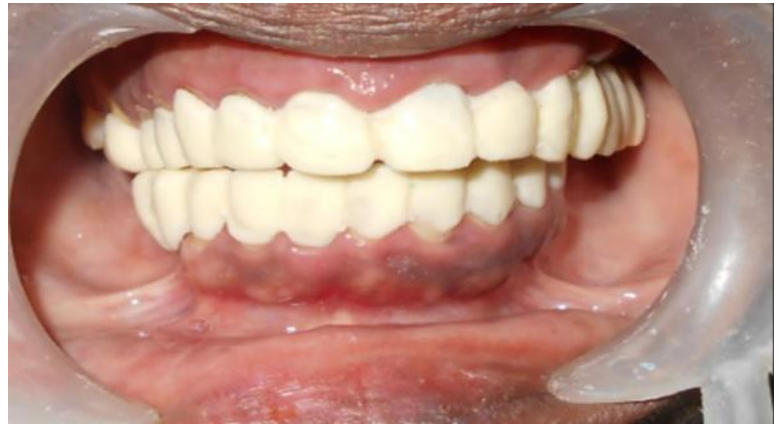

Fig 6: Provisional restoration



Fig 7: Wax pattern for metal coping

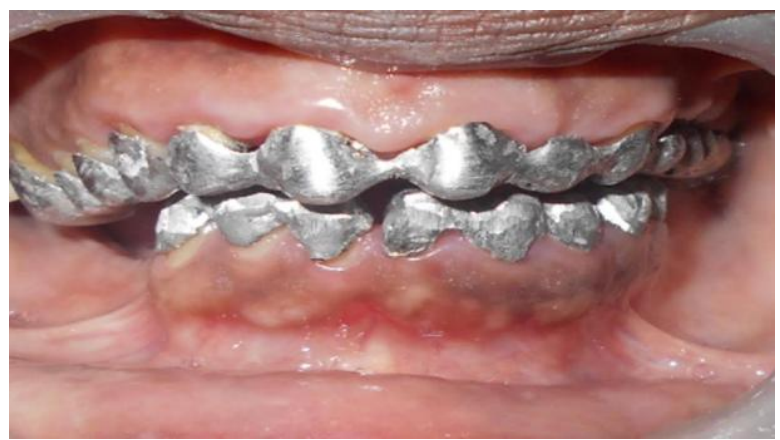

Fig 8: Metal coping

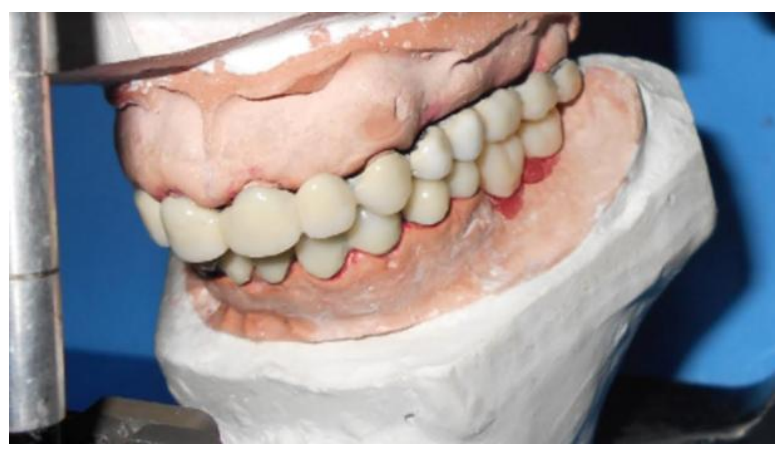

Fig 9: Final Prosthesis 
Rajdeep Tah et al: Full Mouth Rehabilitation Of Severely Worn Dentition With Loss Of Vertical Dimension

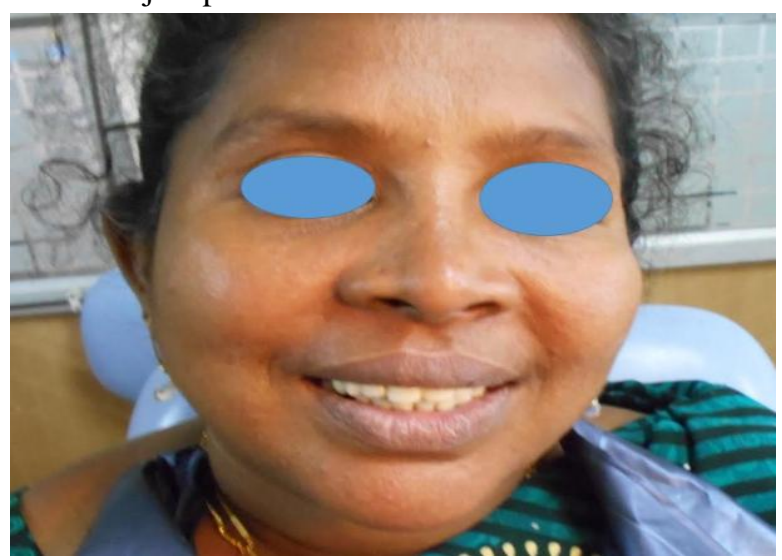

Fig 10: Post-operative (extra oral view)

Then wax pattern for final restoration was done using casting wax.[Fig.7] and casting and finishing was done. Metal try-in was done to verify the fitness and retention of the prosthesis.[Fig.8]Ceramic build-up was done [Fig.9] and cemented with glass ionomer (GC Corporation, Tokyo, Japan).[Fig.10]

\section{DISCUSSION}

Esthetic and functional rehabilitation of severely worn out dentition is more challenging when insufficient space for restoration. Proper diagnosis and well planned strategy is required to enhance the patient's self-esteem, confidence, and quality of life. Full-mouth rehabilitation is involves the complete rehabilitation of the oral cavity, in term of function and esthetics. ${ }^{5}$

The vertical dimension of occlusion is constant and does not change throughout an individual's life. ${ }^{1,6,7}$ There are several procedures for determination of the VDO, and measurement of the freeway space when the mandible is at rest, which is the common way that is employed. ${ }^{8}$ Proper registration and maintaining the correct OVD is the most innate step during rehabilitating of worn out dentition. $^{9,10}$

The rise in VDO was determined by esthetic, phonetics and rest space. If VDO was increased arbitrarily without close evaluation which leads to multiple complications. Depending upon the patient's condition and adaptation capacity, the transition period can be shorten the overall treatment time. ${ }^{11}$

There are many concepts followed for mouth rehabilitation like Hobo's philosophy and Pankey Mann Schuyler philosophy. Pankey Mann Schylur philosophy is one of the most accepted concept with well-organized procedure that permits smooth progresses with less wear and tear on the patient. ${ }^{12}$ Regaining optimum oral health is the prime objective of full mouth rehabilitation procedures and preserve the same throughout the life of a patient. $^{13}$

\section{CONCLUSION}

The complications associated with attritted tooth demand a proper treatment plan and sequencing of therapy for an optimal result. Increasing the vertical dimension of occlusion using temporary fixed partial denture and following with porcelain fused to metal crowns fabrication lead to show successful full mouth rehabilitation for the patient with multiple decayed and early loss of posterior teeth. For a successful occlusal rehabilitation, the dentist should have thorough knowledge about functional occlusion, centric relation, occlusal vertical dimension. Using the Pankey Mann Schuyler philosophy for full mouth rehabilitation can be completed more quickly and easily with more comfort to the patient.

\section{FINANCIAL SUPPORT AND SPONSORSHIP} Nil

\section{CONFLICTS OF INTEREST}

There are no conflicts of interest.

\section{References}

1. Turner KA,Missirlian DM.Restoration of the extremely worn dentition.J Prosthet Dent 1984;52:467-74.

2. Prasad S,Kuracina J, Monaco EA Jr.Altering occlusal vertical dimension provisionally with base metal onlays: A clinical report.J Prosthet Dent 2008;100:338-42.

3. Jain AR,Ariga P.Full mouth rehabilitation of a patient having limited interarch space with manbibular implant retained fixed adoro fused to metal Fp-1 prosthesis and maxillary acrylic removable conventional complete denture.Int $\mathbf{J}$ Oral Implantology Clin Res 2013;4:112-7.

4. Jain AR,Nallaswamy D,Ariga P,Philip JM.Full mouth rehabilitation of a patient with reduced vertical dimension using multiple metal ceramic restorations.Contemp Clin Dent 2013;4:531-5.

5. Kalra A,Sandhu HS,Sahoo NK,Nandi AK, Kalra S.Full-mouth rehabilitation using twin-stage technique.Int J Oral Health Sci 2019;9:40-4.

6. Abduo, J,Lyons, K.Clinical considerations for increasing occlusal vertical dimension: review.Aust Dent J 2012;57: 2-10.

7. Johansson A,mar R. 1994. Identification and management of tooth wear.Int $\mathrm{J}$ Prosthodont 1994;7:506-16.

8. Niswonger M.E.The rest position of the mandible and centric relation.J Am Dent Assoc 1934;21:157282 . 
Rajdeep Tah et al: Full Mouth Rehabilitation Of Severely Worn Dentition With Loss Of Vertical Dimension

9. Johansson A,Johansson AK,Omar R,Carlsson GE.Rehabilitation of the worn dentition.J Oral Rehabil 2008;35:548-566.

10. Brown KE.Reconstruction considerations for severe dental attrition.J Prosthet Dent 1980;44:384-88.

11. Zinzala B,Javiya P,Sethuraman R,Tiwari A,Patel R, Jain J.Functional and esthetical full mouth rehabilitation of a patient with severely worn
dentition:A clinical report.Int J Oral Health Med Res 2017;4(5):42-45.

12. Peter E Dawson.Evaluation, diagnosis and treatment planning of occlusal problems- 2nd edition; Page no. 262-66.

13. Mann, Pankey.Use of P.M instrument in treatment planning and in restoring the lower posterior teeth.J Prosthet Dent 1960;10:135-150. 